\title{
PARTITIONED FUNCTIONAL INEQUALITIES IN BANACH MODULES AND APPROXIMATE ALGEBRA HOMOMORPHISMS
}

\author{
KIL-Woung Jun, JAE-HyeOng BAE And Won-GIL PARK
}

\begin{abstract}
We prove the generalized Hyers-Ulam-Rassias stability of partitioned functional equations in Banach modules over a unital $C^{*}$-algebra. It is applied to show the stability of algebra homomorphisms between Banach algebras associated with partitioned functional equations in Banach algebras.
\end{abstract}

Mathematics subject classification (2000): 47J05, 39B82, 46L05.

Key words and phrases: Stability, partitioned functional inequality, approximate algebra homomorphism, Banach module over $C^{*}$-algebra.

\section{REFERENCES}

[1] R. BADORA, On approximate ring homomorphisms, J. Math. Anal. Appl. 276 (2002), 589-597.

[2] F. Bonsall and J. Duncan, Complete Normed Algebras, Springer-Verlag, New York, Heidelberg and Berlin, 1973.

[3] D. G. Bourgin, Approximately isometric and multiplicative transformations on continuous function rings, Duke Math. J. 16 (1949), 385-397.

[4] D. H. Hyers, G. IsAC AND TH. M. Rassias, Stability of Functional Equations in Several Variables, Birkhäuser, Berlin, Basel and Boston, 1998.

[5] G. ISAC AND TH. M. RASSIAS, On the Hyers-Ulam stability of $\psi$-additive mappings, J. Approx. Theory 72 (1993), 131-137.

[6] B. E. Johnson, An approximately multiplicative map between Banach algebras, J. London Math. Soc. 37 (1988), 294-316.

[7] R. KAdison And G. Pedersen, Means and convex combinations of unitary operators, Math. Scand. 57 (1985), 249-266.

[8] C. PARK, Linear functional equations in Banach modules over a $C^{*}$-algebra, Acta Appl. Math. 77 (2003), 125-161.

[9] TH. M. RASSIAS, On the stability of the linear mapping in Banach spaces, Proc. Amer. Math. Soc. 72 (1978), 297-300.

[10] TH. M. Rassias, On a modified Hyers-Ulam sequence, J. Math. Anal. Appl. 158 (1991), 106-113.

[11] TH. M. Rassias, On the stability of functional equations in Banach spaces, J. Math. Anal. Appl. 251 (2000), 264-284.

[12] TH. M. RASSIAS, On the stability of functional equations and a problem of Ulam, Acta Appl. Math. 62 (2000), 123-130.

[13] TH. M. RASSIAS AND P. ŠEMRL, On the behavior of mappings which does not satisfy Hyers-Ulam stability, Proc. Amer. Math. Soc. 114 (1992), 989-993.

[14] TH. M. Rassias AND P. ŠEMRL, On the Hyers-Ulam stability of linear mappings, J. Math. Anal. Appl. 173 (1993), 325-338.

[15] H. SCHRÖDER, $K$-Theory for Real $C^{*}$-Algebras and Applications, Pitman Research Notes in Mathematics, vol. 290, Longman, Essex, 1993.

[16] T. TRIF, Hyers-Ulam-Rassias stability of a Jensen type functional equation, J. Math. Anal. Appl. 250 (2000), 579-588.

[17] T. TRIF, On the stability of a functional equation deriving from an inequality of Popoviciu for convex functions, J. Math. Anal. Appl. 272 (2002), 604-616. 